\title{
FINDINGS IN CYSTOURETHROGRAPHY THAT SUGGEST LOWER URINARY TRACT DYSFUNCTION IN CHILDREN WITH VESICOURETERAL REFLUX
}

\author{
UBIRAJARA BARROSO JR, ANTONIO J. VINHAES, MILTON BARROS, VIVIAN A. \\ BARROSO, ADRIANO A. CALADO, MIGUEL ZERATI FILHO \\ Section of Pediatric Urology, San Rafael Hospital, and Federal University of Bahia, Salvador, Bahia, and \\ Institute of Urology and Nephrology, São José do Rio Preto, São Paulo, Brazil
}

\begin{abstract}
Purpose: Children with lower urinary tract dysfunction and vesicoureteral reflux, at cystography assessment, frequently present alterations in the lower urinary tract anatomy such as dilated posterior urethra, irregularity of the bladder wall and diverticula. However, the significance of these findings is unknown. The objective of this study is to evaluate the incidence of these findings, their time of disappearance and their correlation with the severity of the reflux.

Materials and Methods: 193 children with vesicoureteral reflux, considered simple, in the age group above 5 years at the moment of diagnosis, were analyzed. The recommendation for followup of these patients was one voiding cystoureterography (VCUG) each year. Only patients with a minimum of 2 VCUGs performed in a period of at least 6 months were considered. The VCUGs were classified as positive and negative in relation to findings that were characteristic of lower urinary tract dysfunction (LUTD).

Results: From the 193 children analyzed, 50 (26\%) presented positive VCUG and 143 negative VCUG. From the patients without symptoms of lower urinary tract dysfunction $(\mathrm{n}=135), 12$ (9\%) presented positive VCUG and $123(91 \%)$ a negative VCUG. From the patients with negative VCUG, $68(48 \%)$ presented unilateral reflux and $75(52 \%)$ presented bilateral reflux. From those with positive VCUG, 26 (52\%) had unilateral reflux and 24 bilateral reflux (48\%). This difference was not statistically significant. A higher incidence of grade II reflux was more evident in patients with negative VCUG and degree III in patients with positive VCUG $(\mathrm{p}<0.05)$.

Conclusions: Our study demonstrated that $64 \%$ of the patients with LUTD and reflux presented findings in the VCUG that suggest dysfunction.
\end{abstract}

Key words: bladder, neurogenic; vesicoureteral reflux; imaging studies; voiding dysfunction Int Braz J Urol. 2004; 30: 504-7

\section{INTRODUCTION}

Usually, the first exam requested in the evaluation of vesicoureteral reflux is voiding cystoureterography (VCUG). It offers the advantage, in a first evaluation, of supplying information about the anatomy of the lower urinary tract, besides grad- ing the reflux (1). The association of vesicoureteral reflux with bladder dysfunction is well established (2). The symptoms that indicate dysfunction of the lower urinary tract are voiding urgency, incontinence with or without urgency, and infrequent voiding $(3,4)$. Children with these symptoms, at cystography assessment, frequently present alterations in the lower uri- 
nary tract anatomy such as expanded posterior urethra, irregularity of the vesical wall that corresponds to trabeculations and thickening of the detrusor, besides the possibility of diverticula. However, the significance of these findings is unknown. The objective of this study is to evaluate the incidence of these findings, their time of disappearance and their correlation with the severity of the reflux.

\section{MATERIALS AND METHODS}

From January 1986 to June 1999, 193 children with vesicoureteral reflux, considered simple type, in the age group above 5 years at the moment of diagnosis were analyzed. The recommendation for follow-up of these patients was one voiding cystoureterography each year. Only patients with a minimum of 2 VCUGs performed in a period of at least 6 months were considered. The results of the VCUGs were evaluated by means of reports from the radiologist and pediatric urologists, which contained the information about bladder anatomy. When there was doubt in relation to the diagnosis we reassessed the images. When the images could not be duly characterized, the patients were excluded from the study. The vast majority of the X-rays were done by just one pediatrician radiologist.

The VCUGs were classified as positive and negative in relation to findings that were characteristic of lower urinary tract dysfunction (LUTD). They corresponded to dilation of the posterior portion of the urethra, irregularity of the vesical wall and diverticula of the bladder. The rate and time of resolution of the findings of the VCUG were studied, i.e., how many and when the positive VCUGs became normal (negative). The grades of reflux were registered, as well as if they were unilateral or bilateral. The children were treated with continuous antibiotic prophylaxis, at low doses, and those with symptoms of the lower urinary tract dysfunction were treated with anticholinergics.

The statistical analysis, to compare the proportions, was done by means of Fisher's exact test or the chi-square test, or by Student's $t$ test for the continuous variables. We considered $p<0.05$ as statistically significant.

\section{RESULTS}

From the 193 children analyzed, 50 (26\%) presented positive VCUG and 143 negative VCUG. From $58(30 \%)$ children that presented symptoms of lower urinary tract dysfunction, 37 (64\%) had a positive VCUG and 21 (36\%) a negative VCUG.

From the patients without symptoms of lower urinary tract dysfunction $(\mathrm{n}=135), 12(9 \%)$ presented positive VCUG and 123 (91\%) one negative VCUG. This difference was statistically significant.

In the group with positive VCUG, 49 were female and 1 male. In the group with negative VCUG, 123 were female and 20 were male. In the patients with LUTD symptoms 56 were female and 2 were male, while for those without LUTD these numbers were 19 and 39 respectively. The gender difference between these groups was statistically significant.

From the patients with negative VCUG, 68 $(48 \%)$ presented unilateral reflux and $75(52 \%)$ presented bilateral reflux. From those with positive VCUG, $26(52 \%)$ had unilateral reflux and 24 bilateral reflux (48\%). This difference was not statistically significant. The correlation between the findings of VCUG according with the grades of reflux is demonstrated on Table-1. A higher incidence of grade II reflux was more evident in patients with negative VCUG and degree III in patients with positive VCUG $(p<0.05)$. The resolution rate was evaluated for the findings of the VCUG. From the 50 positive VCUGs, 30 became negative at an average period of 49 months, varying from 6 to 125 .

\section{COMMENTS}

Our data evidenced that around $25 \%$ of the children with vesicoureteral reflux presented findings that suggest LUTD in the VCUG, with dilation of the posterior urethra, trabeculation of the wall and vesicle diverticula. From the children with LUTD, 64\% presented these findings. What is interesting is that $9 \%$ of the children without LUTD symptoms presented a VCUG that suggests dysfunction. An explanation for this event is that these children may have had neonatal reflux that is associated to LUTD in the large majority of cases (5). In this situation, the VCUG could 
Table 1 - Correlation between the voiding cystoureterography (VCUG) findings and reflux grade.

\begin{tabular}{lccc}
\hline & Positive VCUG (\%) & Negative VCUG (\%) & p value \\
\hline Grade (total) & $8(11)$ & $21(10)$ & $>0.05$ \\
1 & $14(19)$ & $90(41)$ & $<0.05$ \\
2 & $39(53)$ & $78(36)$ & $>0.05$ \\
3 & $13(17)$ & $24(11)$ & \\
4 & 0 & $4(2)$ & \\
5 & 0 & $1(0.5)$ & \\
Undetermined & & & \\
\hline
\end{tabular}

demonstrate alterations, still not presenting symptoms. Sillen et al. have demonstrated that many children who are diagnosed with LUTD at 3 or 4 years of age, may have had a neonatal reflux and the dysfunction may be vestiges from this period (6). Another hypothesis is that these findings in VCUG may not be specific of vesical instability. Batista et al. have made it evident that sensitivity, specificity and accuracy of VCUG findings that suggest instability, when detrusor instability is detected in the urodynamic study, correspond to $0.5,0.62$ and 0.52 respectively (7). Sillen et al. recently reported that VCUG was well correlated with the urodynamic study of children with neonatal reflux (8). Nevertheless this is a select group of patients, in an age group that is different from the one we have studied.

We have not found difference in relation to unilateral or bilateral reflux and the VCUG findings. Scholtmeijer \& Nijman have demonstrated that children with urinary dysfunction more frequently present bilateral reflux than those with urgency syndrome (9). According to our data a VCUG that suggests urinary dysfunction is not predictive of bilateral reflux. Nevertheless, our study made it evident that children with positive VCUG more frequently have grade 3 reflux and those with negative VCUG more commonly have grade 2 reflux. The incidence of grades 1 and 4 reflux was similar between the 2 groups. The meaning of these findings is uncertain. One data that we considered important and that, to our knowledge, was not previously reported, is that the alterations of the VCUG tend to have resolution with time. The average was 49 months. This may reflect a clinical improvement that the patients have obtained with treat- ment, as well as it may be the result of neurophysiological maturation of the lower urinary tract.

\section{CONCLUSIONS}

Our study demonstrated that $64 \%$ of the patients with LUTD and reflux presented findings in the VCUG that suggest dysfunction. These findings were found in $9 \%$ of those without LUTD. In other words, the presence of elements found in the VCUG, such as dilated urethra and bladder trabeculation do not necessarily mean that the patients have LUTD symptoms, as they are only found in a little more than half of the patients with LUTD, demonstrating a low sensitivity. Nevertheless, not indicating bilateral reflux and severe reflux, as it may seem. When these findings are present, they tend to have resolution in 4 years period.

\section{REFERENCES}

1. International reflux study committee: Medical versus surgical treatment of primary vesicoureteral reflux: report of the IRS committee. Pediatrics. 1981; 67: 392400.

2. Barroso U Jr, Jednak R, Barthold JS, Gonzalez R: Outcome of ureteral reimplantation in children with the urge syndrome. J Urol. 2001; 166: 1031-5.

3. van Gool JD, Hjalmas K, Tamminen-Mobius T, Olbing $\mathrm{H}$ : Historical clues to the complex of dysfunctional voiding, urinary tract infection and vesicoureteral reflux. The International Reflux Study in Children. J Urol. 1992; 148: 1699-702.

4. Homsy YL: Dysfunctional voiding syndromes and vesicoureteral reflux. Pediatr Nephrol. 1994; 8: 11621. 
5. Sillen U, Hjalmas K, Aili M, Bjure J, Hanson E, Hansson S: Pronouced detrusor hypercontractility in infants with gross bilateral reflux. J Urol. 1992; 148: 598-9.

6. Sillen U, Bachelard M, Hermanson G, Hjalmas K: Gross bilateral reflux in infants: gradial decrease of initial detrusor hypercontractility. J Urol. 1996; 155: 668-72.

7. Batista Miranda JE, Regalado Pareja R, Garat Barredo JM, Caffaratti J, Arano Bertran P, Gelabert Mas A:
[Vesico-ureteral reflux associated with detrusor instability]. An Esp Pediatr. 1997; 47: 245-50. Spanish.

8. Bachelard M, Verkauskas G, Bertilsson M, Sillen UJ, Jacobsson B: Recognition of bladder instability on voiding cystourethrography in infants with urinary tract infection. J Urol. 2001; 166: 1899-903.

9. Scholtmeijer RJ, Nijman RJ: Vesicoureteric reflux and videourodymanic studies: results of a prospective study after three years of follow-up. Urology. 1994; 43: 71418 .

Received: May 17, 2004

Accepted after revision: November 25, 2004

Correspondence address:

Dr. Ubirajara Barroso Jr.

Rua Alameda dos Antúrios, 212 / 602

Salvador, BA, 40280-620, Brazil

Fax: + 5571 399-6513

E-mail: ubarroso@uol.com.br 